\title{
Erratum zu: Fußballspiele, Polizeieinsätze und Steuerzahler: Ökonomische Anmerkungen zur Polizeikosten-Debatte
}

\author{
Karsten Mause
}

Online publiziert: 14. Juli 2021

(C) Der/die Autor(en) 2021

\section{Erratum zu:}

\section{List Forum 2020}

https://doi.org/10.1007/s41025-020-00190-4

\section{Der Artikel}

Fußballspiele, Polizeieinsätze und Steuerzahler:

Ökonomische Anmerkungen zur Polizeikosten-Debatte von

Karsten Mause

wurde ursprünglich ohne „Open Access“ Online First auf der Internetplattform des Verlags publiziert. Nach der Veröffentlichung im Band 45 Heft 4 pp 423-440 entschieden sich die Autoren nachträglich für eine „Open Access“-Veröffentlichung. Das Urheberrecht des Artikels wurde deshalb zu (C Der/die Autor(en) 2020 geändert.

Funding Open Access funding enabled and organized by Projekt DEAL.

Open Access Dieser Artikel wird unter der Creative Commons Namensnennung 4.0 International Lizenz veröffentlicht, welche die Nutzung, Vervielfältigung, Bearbeitung, Verbreitung und Wiedergabe in jeglichem Medium und Format erlaubt, sofern Sie den/die ursprünglichen Autor(en) und die Quelle ordnungsgemäß nennen, einen Link zur Creative Commons Lizenz beifügen und angeben, ob Änderungen vorgenommen wurden.

Die in diesem Artikel enthaltenen Bilder und sonstiges Drittmaterial unterliegen ebenfalls der genannten Creative Commons Lizenz, sofern sich aus der Abbildungslegende nichts anderes ergibt. Sofern das betreffende Material nicht unter der genannten Creative Commons Lizenz steht und die betreffende Handlung

Die Online-Version des Originalartikels ist unter https://doi.org/10.1007/s41025-020-00190-4 zu finden.

Karsten Mause $(\bowtie)$

Institut für Politikwissenschaft, Universität Münster, Scharnhorststr. 100, 48151 Münster,

Deutschland

E-Mail: karsten.mause@uni-muenster.de 
nicht nach gesetzlichen Vorschriften erlaubt ist, ist für die oben aufgeführten Weiterverwendungen des Materials die Einwilligung des jeweiligen Rechteinhabers einzuholen.

Weitere Details zur Lizenz entnehmen Sie bitte der Lizenzinformation auf http://creativecommons.org/ licenses/by/4.0/deed.de. 